\title{
Undernutrition among adults in India: the significance of individual-level and contextual factors impacting on the likelihood of underweight across sub-populations
}

\author{
Md Zakaria Siddiqui ${ }^{1,2}$ and Ronald Donato ${ }^{3, *}$ \\ ${ }^{1}$ Crawford School of Public Policy, Australian National University, Canberra, Australia: ${ }^{2}$ Institute of Development \\ Studies Kolkata, Kolkata, India: ${ }^{3}$ UniSA Business School, University of South Australia, Way Lee Building, City West \\ Campus, 37-44 North Terrace, Adelaide, SA 5001, Australia
}

Submitted 23 0ctober 2015: Final revision received 7 June 2016: Accepted 20 June 2016: First published online 12 August 2016

\begin{abstract}
Objective: To investigate the extent to which individual-level as well as macrolevel contextual factors influence the likelihood of underweight across adult sub-populations in India.

Design: Population-based cross-sectional survey included in India's National Health Family Survey conducted in 2005-06. We disaggregated into eight sub-populations.

Setting: Multistage nationally representative household survey covering $99 \%$ of India's population.

Subjects: The survey covered 124385 females aged 15-49 years and 74369 males aged 15-54 years.

Results: A social gradient in underweight exists in India. Even after allowing for wealth status, differences in the predicted probability of underweight persisted based upon rurality, age/maturity and gender. We found individual-level education lowered the likelihood of underweight for males, but no statistical association for females. Paradoxically, rural young (15-24 years) females from more educated villages had a higher likelihood of underweight relative to those in less educated villages; but for rural mature ( $>24$ years) females the opposite was the case. Christians had a significantly lower likelihood of underweight relative to other socio-religious groups $(\mathrm{OR}=0.53-0 \cdot 80)$. Higher state-level inequality increased the likelihood of underweight across most population groups, while neighbourhood inequality exhibited a similar relationship for the rural young population subgroups only. Individual states/neighbourhoods accounted for $5-9 \%$ of the variation in the prediction of underweight. We found that rural young females represent a particularly highly vulnerable sub-population.

Conclusions: Economic growth alone is unlikely to reduce the burden of malnutrition in India; accordingly, policy makers need to address the broader social determinants that contribute to higher underweight prevalence in specific demographic subgroups.
\end{abstract}

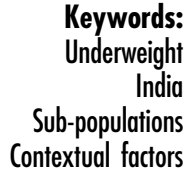

Despite the high economic growth rates in India over the past two decades, the level of undernutrition among the Indian population remains persistently high. The most recent United Nations estimates (2012-2014) reveal that India has the highest number of undernourished people in the world (190 million), representing $15 \%$ of its entire population and $50 \%$ proportionately more than China ${ }^{(1)}$. Undernutrition levels remain higher in India than in most countries in sub-Saharan Africa despite those countries having lower public health infrastructure, lower levels of economic development and higher infant and child mortality rates ${ }^{(2)}$. The ability to be well nourished represents a key element of human freedom and is central to human well-being; undernutrition, therefore, denies the opportunity for individuals to lead a minimally healthy life ${ }^{(3,4)}$. Compared with those who are well fed, malnourished individuals are more vulnerable to infectious diseases, have a higher mortality rate and are less productive at work ${ }^{(5,6)}$. For females, undernutrition during pregnancy increases their babies' risk for disease, physical retardation and impaired cognitive capabilities, and increases the risk of maternal mortality ${ }^{(6-8)}$.

While the connection between poverty and undernutrition and its consequent distributional impact have 
been relatively well described, the configuration of undernutrition across particular sub-populations in India in the context of geographical and sociocultural features has received limited attention. Although some studies have explored the influence of geography and socio-economic factors on the risk of underweight, population groups have been aggregated, which tends to obscure the varying underlying factors impacting on particular sub-populations ${ }^{(9-11)}$. The aim of the present study was to analyse a nationally representative health survey data set and investigate the extent to which individual-level covariates as well as macro-level contextual factors influence the patterning in the likelihood of underweight across particular adult sub-populations in India. The study contributes to the literature in the following ways: (i) by disaggregating into separate population groups we are able to distinguish the particular factors influencing the likelihood of underweight; and (ii) we explore the extent to which individual- and macro-level contextual factors matter and so highlight the need to acknowledge the socio-environmental circumstances impacting on the likelihood of underweight. The present paper argues that relying on economic growth alone will not be sufficient to tackle the burden of malnutrition and therefore from a policy perspective there is a need to understand the broader social determinants that impact on health inequalities across population groups.

\section{Methods}

\section{Data and measurements}

We utilised the latest available National Family Health Survey (2005-06; NFHS-3), a household survey which provides information on health-related matters, including fertility, morbidity and mortality, family planning and nutrition, across India. The NFHS-3 covers a nationally representative sample of 124384 females (aged 15-49 years) and 74369 males (aged 15-54 years) across twenty-nine states. The primary sampling unit (PSU) is divided into urban (wards or municipal localities) and rural (villages) and is drawn separately from each state proportional to both its own size and the relative size of the urban and rural populations within that state. BMI was used as the primary outcome measure collected in the survey, calculated as weight in kilograms divided by the square of height in metres $\left(\mathrm{kg} / \mathrm{m}^{2}\right)$. The current study used the WHO classification of undernutrition, where BMI $<18.5 \mathrm{~kg} / \mathrm{m}^{2}$ distinguishes this group from the rest of the population in the survey (i.e. BMI $\geq 18.5 \mathrm{~kg} / \mathrm{m}^{2}$ ). The focus of the study was on analysing the factors associated with the likelihood of being underweight relative to the rest of the Indian population who were not underweight.

Descriptive statistics revealed a substantial difference in the prevalence of underweight between the urban and rural populations, and the younger age categories
(15-19 years in particular) had higher prevalence rates than older population groups (see online supplementary material, Supplemental Table 1). Moreover, gender differences in the prevalence of underweight emerged across particular age groups in the rural sector. Preliminary modelling revealed that model covariates were responding differently across particular age groupings (i.e. young $v$. older age cohorts), between genders (i.e. males $v$. females) and by rurality (i.e. urban $v$. rural residence). Given that the possible differences across these subpopulation groups might not be explained by standard covariates or are obscured by aggregation, we separated the analysis into eight population groups: young (15-24 years) and mature ( $>24$ years) rural and urban females, and young (15-24 years) and mature ( $>24$ years) rural and urban males. Disaggregating the population enabled us to investigate the differing effects of particular individual- and macro-level contextual factors that impact on the likelihood of underweight across adult Indian sub-populations.

\section{Individual-level covariates}

Drawing on the empirical literature analysing possible influences on the likelihood of underweight as well as our own preliminary statistical analyses, the present study incorporated several individual-level variables in the model framework. These included economic status, education, age, religion/caste, births, occupation, toilet facilities, clean cooking fuel and tobacco use. For economic status, NFHS-3 adopted a wealth index score based on household ownership of particular assets and each individual in the household was assigned the same wealth score. As with other studies, our analysis adopted this measure as a continuous variable. Education was divided into six categorical variables: 0 years (no education), 1-5 years (primary), 6-8 years (middle school), 9-10 years (junior secondary), 11-12 years (senior secondary) and $>12$ years (tertiary). Age was treated as a categorical variable divided into 5 -year spans from age 15 to 49 years for females and from 15 to 54 years for males. However, as mentioned, given the differing responsiveness to covariates across the age groupings we separated the population into 'young', which encompasses the categories of 15-19 and 20-24 years, and 'mature', which encompasses the 25-29, 30-34, 35-39, 40-44, 45-49 and 50-54 years (for males) groups. (Our modelling exercise revealed that the 20-24 years category exhibited similar characteristics to the 15-19 years category in its association with particular covariates, hence the inclusion of both age categories in the 'young' sub-population.)

To reflect the possible impact of socio-cultural dimensions influencing the likelihood of underweight, religion and caste were incorporated into a single categorical variable. Hindus were divided into two 
sub-categories: Hindu - caste (which included scheduled castes, scheduled tribe and other backward castes) and Hindu - general (containing all Hindus not included in Hindu - caste). The other main religious groupings incorporated into the analyses were Muslims, Sikhs and Christians. Occupation was divided into three categories: not working/home, white collar and manual labour. In order to capture the possible influence of 'public infrastructure' on the likelihood of underweight, the present study adopted a similar approach to that taken by Jose and Navaneetham ${ }^{(12)}$ and included access to toilet facilities (to distinguish those households that were exposed to open defecation) and access to 'clean' cooking fuel (kerosene, gas and electricity) vis-à-vis 'biofuel' cooking (smoke-related solid fuels such as wood, coal and biomass) as covariates in the analysis.

\section{Macro-level contextual factors}

A considerable body of literature has emerged which has moved beyond individual-level behaviour to explore the significance of particular sociocultural and geographically related influences as important determinants of health and nutritional status. Drawing on other empirical studies as well the observed effects of our preliminary modelling exercises across different sub-populations, the present study incorporated a number of macro-level social and geographically related contextual factors in the analysis. To assess the possible independent effects of state-level standards of living, we used the household monthly per capita expenditure for rural and urban areas for each state (i.e. 'state per capita expenditure'). This was obtained from a consumption expenditure survey conducted in 2004-05 by the National Sample Survey Office. In addition, to incorporate the possible influence of economic inequality on the likelihood of underweight, the study adopted a similar approach to that of Subramanian et al. $^{(13)}$ and included two measures of inequality - state and neighbourhood (PSU) levels - in the analysis. At the state level we used a standardised $(Z)$ score of the Gini coefficient of per capita consumption calculated separately for rural and urban areas using the National Sample Survey Office 2004-05 data (i.e. 'state inequality'). At the neighbourhood level, an inequality measure of wealth using the $\mathrm{CV}$ was calculated from the NFHS-3 data (i.e. 'neighbourhood inequality'). Finally, in order to explore the possible effects of the broader educational environment on the likelihood of underweight the current study followed a similar method to one used by Mowafi et al. ${ }^{(14)}$ and included a neighbourhood education variable based on the percentage of females in a given neighbourhood/village having $\geq 10$ years of education (i.e. 'neighbourhood education'). The descriptive statistics for predictor variables considered in the study, in terms of sample size and percentage of underweight, tabulated across the eight sub-populations, are shown in the online supplementary material, Supplemental Table 1. We also include descriptive statistics of the prevalence of underweight by individual state across each of the eight sub-populations in Supplemental Table 2.

\section{Statistical analysis}

A multilevel binomial logit regression model was used to estimate a binary outcome in terms of a log likelihood ratio of underweight. The model is expressed as

$$
\ln \left(\frac{\phi_{i j k}}{1-\phi_{i j k}}\right)=\alpha \sum_{m} \beta^{m} X_{i j k}^{m}+u_{k}+v_{j k}+e_{i j k},
$$

where:

$\phi_{i j k}$ is the probability of underweight for individual $i$ nested in the $j$ th PSU nested in the $k$ th state;

$X_{i j k}^{m}$ are fixed component covariates, where superscript $m$ represents the number of covariates;

$u_{k}$ is the intercept effect of the $k$ th state;

$v_{j k}$ is the intercept effect of the $j$ th PSU nested in the $k$ th state; and

$e_{i j k}$ is the residual error of individual $i$ nested in the $j$ th PSU nested in the $k$ th state.

The model shown in equation (1) contains a fixed component which has a separate intercept $(\alpha)$ and a slope parameter $\left(\beta^{m}\right)$ estimating the effects of a one-unit change in the covariates on the log of the odds of being underweight $(\phi)$ relative to not being underweight $(1-\phi)$. Thus the array of covariates (i.e. $X_{i j k}^{m}$ ) included in the model encompasses the individual-level variables of wealth, education, age, births, religion/caste, occupation, cooking fuel type and tobacco use, as well as macro-level contextual variables of state per capita expenditure, state inequality, neighbourhood inequality and neighbourhood education. The remaining terms in equation (1) represent the independent effects of the state (i.e. $u_{k}$ ) and within it the PSU (i.e. $v_{j k}$ ) in which the individuals reside as a separate explanatory variable on the log likelihood of underweight. The advantage of using a multilevel approach of modelling state and neighbourhood effects independently is that it captures unobserved geographically related contextual factors on the likelihood of underweight beyond that explained by individual-level covariates and macro-level factors explicitly included in the model. Thus, the intercept for any given state and PSU can be expressed as $\alpha+u_{k}$ and $\alpha+u_{k}+v_{j k}$, respectively.

Eight separate regression models were generated, one for each sub-population as follows: rural young females, rural mature females, urban young females, urban mature females, rural young males, rural mature males, urban young males and urban mature males. For each of the sub-populations the likelihood or OR of underweight (i.e. $\mathrm{BMI}<18.5 \mathrm{~kg} / \mathrm{m}^{2}$ ) was estimated relative to the rest of the Indian population (i.e. BMI $\geq 18 \cdot 5 \mathrm{~kg} / \mathrm{m}^{2}$ ). ${ }^{*}$

\footnotetext{
* We also performed a similar analysis involving a truncated sample set in which we modelled the likelihood of those underweight relative to
} Indians of normal weight only (i.e. excluding all those overweight and 
In addition, we used the model estimates to transform the likelihood ratio for some of the covariates into an average probability function of underweight at different parameter levels. The average probability of being underweight is based on the predicted probability of each individual by keeping all their characteristics in the sub-population the same in accordance with the estimated model except for the one covariate of interest which can vary. The predicted probability for the sub-population is then calculated at different values of the particular covariate. (We report the predicted probabilities for wealth, neighbourhood education, and state-level and neighbourhood inequalities.) All econometric analyses were conducted using the statistical software package Stata 12.

\section{Results}

Tables 1 and 2 present the binomial logistic regression results for the four female and four male sub-populations, respectively. The categorical parameter estimates are expressed in terms of the OR and the $95 \% \mathrm{CI}$ for the risk of underweight relative to the reference category within the sub-population. The results indicate the parameter estimates that are statistically significant at either $P<0.05$ or $P<0.001$. For each of the eight regression results, we considered all the covariates together in the model to generate respective parameter estimates.

As expected, the results presented in Tables 1 and 2 reveal a strong negative association between wealth and the likelihood of underweight across all sub-population groups (i.e. a parameter estimate $<1$ ): the greater the wealth of an individual, the lower is the likelihood of underweight. Interestingly, the influence of wealth appears to be more pronounced among urban mature subgroups compared with rural and young populations. To interpret this relationship more readily, we calculated the predicted probability of underweight for each sub-population at different levels of wealth (1st, 25th, 50th, 75th and 99th percentile values). The average probabilities of underweight across the four female and four male sub-populations are shown in Fig. 1(a) and Fig. 1(b), respectively.

Fig. 1(a) and Fig. 1(b) reveal similar patterns of declining probability of underweight with increasing wealth, with some degree of convergence at high wealth levels between urban and rural settings. However, there are some notable differences along the wealth spectrum for some of the sub-populations - specifically, between urban and rural settings for mature females and between the young and mature subgroups. For example, at the 25 th percentile of wealth, Fig. 1(a) shows that the predicted probability of being underweight for rural mature females is

obese). The findings reported in the 'Results' section, representing the entire Indian population survey, differed very little from those generated by the truncated sample which excluded those Indians who were overweight and obese.
$37 \cdot 8 \%$ while for urban mature females it is $17.8 \%$ - a gap of twenty percentage points. At the 99th wealth percentile, the predicted probability of underweight declines for both of these subgroups to 12.1 and $5.0 \%$, respectively, but a sizeable gap still remains between rural and urban mature females. For mature males there is a greater degree of convergence in predicted probability at high wealth levels (i.e. 3.3 and $1.3 \%$ for rural and urban males, respectively, at the 99th percentile; Fig. 1(b)). Fig. 1(a) and Fig. 1(b) show that rising wealth levels do not lead to a convergence in the predicted probability of underweight between the young and the mature sub-population groups, which suggests that a structural difference exists between the age groupings. The results also show there are persistent differences in predicted probability of underweight between mature females and males along the wealth spectrum. For instance, at the 50th percentile the predicted probability for rural mature females is $31.5 \%$ (Fig. 1(a)) while for rural mature males it is $11.6 \%$ (Fig. 1(b)); at the 99th percentile the predicted probabilities are 12.1 and $3.3 \%$, respectively. Gender differences in predicted probabilities also occur along the wealth spectrum in the urban setting although the gap is not as pronounced at very high wealth levels.

Tables 1 and 2 show that age is negatively associated with the risk of underweight. Thus, for example, in the case of the mature sub-population groups the OR of underweight for rural and urban females aged 45-49 years is 0.46 and 0.73 , respectively, relative to the reference group of females aged 25-29 years; for mature rural and urban male sub-populations aged $45-49$ years the OR is 0.89 and 0.62 , respectively, relative to the reference group of males aged 25-29 years.

Tables 1 and 2 also show that Christians stand apart from other religious/caste groupings in having a substantially lower likelihood of underweight relative to the Hindu reference group. This is particularly noticeable for the younger rural sub-populations, where Christian females and males have OR of 0.67 and 0.53 , respectively, relative to the Hindu - general reference group. Similarly, the OR for mature rural females and males are 0.73 and 0.59 , respectively. Young and mature rural male and rural mature female Sikh sub-populations have substantially lower OR than the Hindu - general reference group. The Hindu - caste group has a statistically significant higher likelihood of underweight for three of the four female sub-population categories, with OR ranging from 1.07 to $1 \cdot 18$ compared with the Hindu - general reference group. Interestingly, young and mature urban females with at least one birth have a lower likelihood of underweight (i.e. OR ranging from 0.77 to $0 \cdot 84$ ) relative to females who have not given birth. However, no statistical association is found for rural females in the likelihood of underweight between females with and without birth(s).

The impact of education on the likelihood of underweight warrants particular attention. For all four male 
Table 1 Multilevel logit model for underweight females in India, 2005-06

\begin{tabular}{|c|c|c|c|c|c|c|c|c|}
\hline \multirow[b]{2}{*}{ Fixed parameters $†$} & \multicolumn{2}{|c|}{$\begin{array}{c}\text { Rural young females } \\
\text { (15-24 years) } \\
n 25116\end{array}$} & \multicolumn{2}{|c|}{$\begin{array}{c}\text { Rural mature females } \\
\text { (25-49 years) } \\
n 40409 \\
\end{array}$} & \multicolumn{2}{|c|}{$\begin{array}{c}\text { Urban young females } \\
\text { (15-24 years) } \\
n 19355 \\
\end{array}$} & \multicolumn{2}{|c|}{$\begin{array}{c}\text { Urban mature females } \\
\text { (25-49 years) } \\
n 33792\end{array}$} \\
\hline & OR & $95 \% \mathrm{Cl}$ & OR & $95 \% \mathrm{Cl}$ & OR & $95 \% \mathrm{Cl}$ & OR & $95 \% \mathrm{Cl}$ \\
\hline Wealth & $0 \cdot 80^{\star *}$ & $0.75,0.84$ & $0.57^{\star *}$ & $0.54,0.60$ & $0.71^{\star \star}$ & $0.66,0.75$ & $0.40^{\star \star}$ & $0.46,0.52$ \\
\hline \multicolumn{9}{|l|}{ Education (years) } \\
\hline 0 (ref.) & 1.00 & - & 1.00 & - & 1.00 & - & 1.00 & - \\
\hline $1-5$ & 1.02 & $0.94,1.12$ & $0.89^{*}$ & $0.84,0.96$ & 0.94 & $0.82,1.09$ & $0.90^{\star}$ & $0.81,0.99$ \\
\hline $6-8$ & 1.08 & $0.99,1.18$ & 0.93 & $0.86,1.01$ & 1.08 & $0.95,1.23$ & 0.95 & $0.85,1.05$ \\
\hline $9-10$ & $1 \cdot 15^{\star}$ & $1.04,1.26$ & 0.98 & $0.89,1.09$ & 1.08 & $0.95,1.23$ & 0.99 & $0.88,1 \cdot 11$ \\
\hline $11-12$ & 1.10 & $0.97,1.24$ & 0.86 & $0.73,1.01$ & 1.08 & $0.94,1.25$ & 0.92 & $0.79,1.07$ \\
\hline$>12$ & $1 \cdot 10$ & $0.93,1.31$ & 1.06 & $0.88,1.26$ & 1.01 & $0.86,1.19$ & 0.98 & $0.84,1.13$ \\
\hline \multicolumn{9}{|l|}{ Age (years) } \\
\hline 15-19 (ref.) & 1.00 & - & & & 1.00 & - & & \\
\hline $20-24$ & $0.74^{\star \star}$ & $0.70,0.79$ & & & $0.68^{\star \star}$ & $0.63,0.74$ & & \\
\hline 25-29 (ref.) & & & 1.00 & - & & & 1.00 & - \\
\hline $30-34$ & & & $0.92^{*}$ & $0.86,0.98$ & & & $0.69^{\star \star}$ & $0.63,0.75$ \\
\hline $35-39$ & & & $0.78^{\star \star}$ & $0.73,0.84$ & & & $0.56^{\star \star}$ & $0.51,0.61$ \\
\hline $40-44$ & & & $0.73^{\star \star}$ & $0.68,0.79$ & & & $0.45^{\star \star}$ & $0.40,0.50$ \\
\hline $45-49$ & & & $0.73^{\star \star}$ & $0.67,0.79$ & & & $0.46^{\star \star}$ & $0.40,0.52$ \\
\hline \multicolumn{9}{|l|}{ Births } \\
\hline 0 (ref.) & 1.00 & - & 1.00 & - & 1.00 & - & 1.00 & - \\
\hline 1 ( $\geq 1$; young only) & 1.07 & $0.99,1.14$ & 0.92 & $0.81,1.04$ & $0.80^{\star \star}$ & $0.73,0.88$ & $0.78^{\star \star}$ & $0.68,0.89$ \\
\hline 2 & & & 0.91 & $0.82,1.01$ & & & $0 \cdot 77^{\star \star}$ & $0.69,0.87$ \\
\hline 3 & & & 0.91 & $0.82,1.01$ & & & $0.79^{\star \star}$ & $0.70,0.90$ \\
\hline$\geq 4$ & & & 1.00 & $0.90,1.11$ & & & $0 \cdot 84^{*}$ & $0.74,0.96$ \\
\hline \multicolumn{9}{|l|}{ Religion } \\
\hline Hindu - general (ref.) & 1.00 & - & 1.00 & - & 1.00 & - & 1.00 & - \\
\hline Muslim & 1.06 & $0.94,1.19$ & 0.94 & $0.85,1.04$ & 1.02 & $0.91,1.14$ & $0.86^{\star}$ & $0.76,0.96$ \\
\hline Christian & $0.67^{\star *}$ & $0.56,0.80$ & $0.73^{\star \star}$ & $0.63,0.85$ & 0.93 & $0.78,1.11$ & $0.80^{\star}$ & $0.67,0.96$ \\
\hline Sikh & 1.09 & $0.85,1.41$ & $0.75^{\star}$ & $0.57,0.97$ & 0.97 & $0.70,1.35$ & 0.75 & $0.49,1.13$ \\
\hline Hindu - caste & 1.01 & $0.93,1.10$ & $1.07^{\star}$ & $1.00,1.15$ & $1 \cdot 18^{\star \star}$ & $1.09,1.30$ & $1 \cdot 13^{\star}$ & $1.03,1.22$ \\
\hline Other & $0.77^{\star}$ & $0.62,0.96$ & $0.73^{\star}$ & $0.60,0.87$ & 1.05 & $0.86,1.28$ & 1.05 & $0.86,1.28$ \\
\hline \multicolumn{9}{|l|}{ Occupation } \\
\hline Not working (ref.) & 1.00 & - & 1.00 & - & 1.00 & - & 1.00 & - \\
\hline White collar & $1 \cdot 10$ & $0.95,1.29$ & $0.86^{*}$ & $0.78,0.96$ & 1.01 & $0.91,1.12$ & 0.98 & $0.90,1.08$ \\
\hline Manual labour & 1.04 & $0.97,1.11$ & $1 \cdot 11^{\star \star}$ & $1.05,1.17$ & 1.04 & $0.94,1.16$ & $1 \cdot 29^{\star \star}$ & $1.18,1.41$ \\
\hline \multicolumn{9}{|l|}{ Cooking } \\
\hline Biomass (ref.) & 1.00 & - & 1.00 & - & 1.00 & - & 1.00 & - \\
\hline Clean fuel & 1.01 & $0.90,1.13$ & $0.80^{\star \star}$ & $0.72,0.88$ & $1 \cdot 12^{*}$ & $1.02,1.22$ & 0.96 & $0.88,1.06$ \\
\hline \multicolumn{9}{|l|}{ Toilet facilities } \\
\hline Yes (ref.) & 1.00 & - & 1.00 & - & 1.00 & - & 1.00 & - \\
\hline No (open defecation) & $1 \cdot 20^{\star \star}$ & $1 \cdot 12,1 \cdot 29$ & $1 \cdot 11^{*}$ & $1.04,1.19$ & 0.92 & $0.81,1.05$ & 0.90 & $0.80,1.01$ \\
\hline \multicolumn{9}{|l|}{ Tobacco } \\
\hline No (ref.) & NA & & 1.00 & - & NA & & 1.00 & - \\
\hline Yes & & & $1.32^{\star \star}$ & $1.22,1.43$ & & & 1.06 & $0.93,1.21$ \\
\hline State per capita expenditure & $0.99^{\star \star}$ & $0.99,0.99$ & $0.99^{\star \star}$ & $0.99,0.99$ & $0.94^{*}$ & $0.88,0.99$ & $0.88^{\star \star}$ & $0.83,0.94$ \\
\hline State inequality & $1.35^{\star \star}$ & $1.19,1.55$ & $1.28^{\star \star}$ & $1.13,1.46$ & $1 \cdot 17^{*}$ & $1.04,1.33$ & 1.08 & $0.95,1.22$ \\
\hline Neighbourhood inequality & $1.45^{\star}$ & $1.12,1.88$ & $1 \cdot 12$ & $0.89,1.40$ & 1.01 & $0.99,1.01$ & 1.00 & $0.99,1.01$ \\
\hline Neighbourhood education & $1.57^{\star}$ & $1.18,2.08$ & $0.69^{*}$ & $0.54,0.88$ & 0.99 & $0.99,1.00$ & $0.99^{\star \star}$ & $0.99,0.99$ \\
\hline Constant & 1.41 & $0.84,2.37$ & $2 \cdot 39^{*}$ & $1.44,3.98$ & $2 \cdot 20^{*}$ & $1.05,4.62$ & $6 \cdot 6^{* *}$ & $3.12,13.98$ \\
\hline Random effects & ICC $\ddagger$ & $95 \% \mathrm{Cl}$ & ICC $\ddagger$ & $95 \% \mathrm{Cl}$ & ICC $\ddagger$ & $95 \% \mathrm{Cl}$ & ICC $\ddagger$ & $95 \% \mathrm{Cl}$ \\
\hline State & $0.03^{*}$ & $0.01,0.05$ & $0.03^{*}$ & $0.01,0.05$ & $0.03^{*}$ & $0.01,0.05$ & $0.03^{*}$ & $0.01,0.05$ \\
\hline State/PSU & $0.07^{\star \star}$ & $0.05,0.09$ & $0.07^{\star \star}$ & $0.05,0.08$ & $0.06^{\star \star}$ & $0.05,0.09$ & $0.06^{\star \star}$ & $0.04,0.07$ \\
\hline
\end{tabular}

ref., reference category; PSU, primary sampling unit; NA, not applicable; ICC, intraclass correlation.

${ }^{\star} P<0.05,{ }^{* \star} P<0.001$.

†From equation (1) we use $\exp \left(\beta^{1}\right)$, which is the effect of a one-unit increase in the covariate on the odds of being underweight.

¥ICC measures the proportion of the total unexplained variance attributable to differences between states/PSU after considering all independent variables in the model.

sub-populations, Table 2 shows that higher levels of education reduce the likelihood of underweight. Thus, for the male population with more than 12 years' education the OR is about half $(0.46-0.63)$ that of the respective reference group with no education. In the case of females, there appears to be no association between individual- level education and the likelihood of underweight across all sub-populations. Interestingly, however, model results reveal there is a statistically significant association between the neighbourhood (PSU) education level (i.e. 'neighbourhood education', representing the proportion of females in the PSU with $\geq 10$ years of education) and 
Table 2 Multilevel logit model for underweight males in India, 2005-06

\begin{tabular}{|c|c|c|c|c|c|c|c|c|}
\hline \multirow[b]{2}{*}{ Fixed parameters } & \multicolumn{2}{|c|}{$\begin{array}{c}\text { Rural young males } \\
\text { (15-24 years) } \\
n 11425\end{array}$} & \multicolumn{2}{|c|}{$\begin{array}{l}\text { Rural mature males } \\
\text { (25-54 years) } \\
n 23058\end{array}$} & \multicolumn{2}{|c|}{$\begin{array}{l}\text { Urban young males } \\
\begin{array}{c}\text { (15-24 years) } \\
n 12251\end{array}\end{array}$} & \multicolumn{2}{|c|}{$\begin{array}{c}\text { Urban mature males } \\
\text { (25-54 years) } \\
n 22334\end{array}$} \\
\hline & OR & $95 \% \mathrm{Cl}$ & OR & $95 \% \mathrm{Cl}$ & OR & $95 \% \mathrm{Cl}$ & OR & $95 \% \mathrm{Cl}$ \\
\hline Wealth & $0.78^{\star \star}$ & $0.73,0.86$ & $0.54^{\star \star}$ & $0.51,0.58$ & $0.71^{* *}$ & $0.66,0.77$ & $0.47^{\star \star}$ & $0.43,0.50$ \\
\hline \multicolumn{9}{|l|}{ Education (years) } \\
\hline 0 (ref.) & 1.00 & - & 1.00 & - & 1.00 & - & 1.00 & - \\
\hline $1-5$ & 0.91 & $0.77,1.08$ & $0.91^{*}$ & $0.83,0.99$ & $1 \cdot 15$ & $0.93,1.42$ & 1.02 & $0.89,1.17$ \\
\hline $6-8$ & 1.01 & $0.86,1.18$ & $0.84^{*}$ & $0.76,0.93$ & $1 \cdot 11$ & $0.91,1.35$ & 0.88 & $0.77,1.01$ \\
\hline $9-10$ & 0.88 & $0.74,1.04$ & $0.77^{\star \star}$ & $0.70,0.86$ & 1.02 & $0.84,1.25$ & $0.82^{*}$ & $0.72,0.95$ \\
\hline $11-12$ & $0.57^{\star *}$ & $0.47,0.69$ & $0.68^{\star *}$ & $0.59,0.79$ & $0.73^{*}$ & $0.59,0.90$ & $0.83^{*}$ & $0.70,0.99$ \\
\hline$>12$ & $0.46^{\text {** }}$ & $0.36,0.59$ & $0.63^{* *}$ & $0.53,0.74$ & $0.58^{* \star}$ & $0.46,0.73$ & $0.54^{\star *}$ & $0.45,0.65$ \\
\hline \multicolumn{9}{|l|}{ Age (years) } \\
\hline $15-19$ (ref.) & 1.00 & - & & & 1.00 & - & & \\
\hline $20-24$ & $0.43^{\star \star}$ & $0.39,0.47$ & & & $0.45^{\star \star}$ & $0.41,0.50$ & & \\
\hline $25-29$ (ref.) & & & 1.00 & - & & & 1.00 & - \\
\hline $30-34$ & & & $0.83^{* *}$ & $0.76,0.92$ & & & $0.69^{* *}$ & $0.62,0.78$ \\
\hline $35-39$ & & & $0.79^{* *}$ & $0.72,0.87$ & & & $0.51^{* *}$ & $0.45,0.58$ \\
\hline $40-44$ & & & $0.79^{\star *}$ & $0.71,0.87$ & & & $0.59^{\star *}$ & $0.52,0.67$ \\
\hline $45-49$ & & & $0.89^{\star}$ & $0.80,0.99$ & & & $0.62^{* *}$ & $0.54,0.71$ \\
\hline $50-54$ & & & 0.92 & $0.82,1.05$ & & & $0.61^{\star *}$ & $0.52,0.71$ \\
\hline \multicolumn{9}{|l|}{ Religion } \\
\hline Hindu - general (ref.) & 1.00 & - & 1.00 & - & 1.00 & - & 1.00 & _- \\
\hline Muslim & 0.96 & $0.80,1.15$ & 0.94 & $0.82,1.09$ & $1 \cdot 10$ & $0.95,1.27$ & 0.97 & $0.85,1.12$ \\
\hline Christian & $0.53^{\star \star}$ & $0.41,0.68$ & $0.59^{\star *}$ & $0.48,0.72$ & $0.69^{*}$ & $0.55,0.87$ & $0.71^{*}$ & $0.56,0.89$ \\
\hline Sikh & 0.78 & $0.51,1.20$ & $0.54^{*}$ & $0.35,0.81$ & 0.93 & $0.57,1.52$ & 0.64 & $0.34,1.19$ \\
\hline Hindu - caste & 0.99 & $0.87,1.12$ & 1.04 & $0.95,1.14$ & $1 \cdot 15^{\star}$ & $1.02,1.28$ & 1.02 & $0.92,1.14$ \\
\hline Other & $0.68^{\star}$ & $0.50,0.93$ & 0.82 & $0.65,1.05$ & 1.22 & $0.95,1.57$ & 1.14 & $0.91,1.44$ \\
\hline \multicolumn{9}{|l|}{ Occupation } \\
\hline Not working (ref.) & 1.00 & - & 1.00 & - & 1.00 & - & 1.00 & - \\
\hline White collar & $0.57^{\star *}$ & $0.49,0.66$ & $0.56^{\star \star}$ & $0.44,0.71$ & $0.67^{\star *}$ & $0.59,0.75$ & $0.61^{\star *}$ & $0.49,0.76$ \\
\hline Manual labour & $0.59^{\text {** }}$ & $0.53,0.67$ & $0.63^{\star \star}$ & $0.49,0.79$ & $0.72^{\star \star}$ & $0.64,0.82$ & $0.69^{\star}$ & $0.55,0.85$ \\
\hline \multicolumn{9}{|l|}{ Toilet facilities } \\
\hline Yes (ref.) & 1.00 & - & 1.00 & - & 1.00 & - & 1.00 & - \\
\hline No (open defecation) & $1 \cdot 16^{\star}$ & $1.03,1.33$ & 1.02 & $0.93,1.13$ & 0.92 & $0.78,1.08$ & 0.98 & $0.86,1.12$ \\
\hline \multicolumn{9}{|l|}{ Tobacco } \\
\hline No (ref.) & 1.00 & - & 1.00 & - & 1.00 & - & 1.00 & - \\
\hline Yes & 0.96 & $0.85,1.09$ & 0.94 & $0.87,1.01$ & 1.01 & $0.89,1.17$ & 1.06 & $0.96,1.17$ \\
\hline State per capita expenditure & $0.88^{*}$ & $0.81,0.95$ & $0.88^{\star *}$ & $0.83,0.94$ & $0.92^{*}$ & $0.85,0.99$ & $0.91^{*}$ & $0.86,0.96$ \\
\hline State inequality & $1.44^{\star *}$ & $1.24,1.68$ & $1.34^{* *}$ & $1.18,1.52$ & $1.22^{*}$ & $1.04,1.43$ & $1.13^{\star}$ & $1.02,1.27$ \\
\hline Neighbourhood inequality & $1.01^{*}$ & $1.00,1.01$ & 1.00 & $0.99,1.00$ & 1.00 & $0.99,1.00$ & $0.99^{*}$ & $0.99,0.99$ \\
\hline Neighbourhood education & 1.00 & $0.99,1.00$ & 0.99 & $0.99,1.00$ & 1.00 & $0.99,1.00$ & 0.99 & $0.99,1.00$ \\
\hline Constant & $3.38^{\star \star}$ & $1.78,6 \cdot 40$ & 1.22 & $0.70,2.13$ & $3 \cdot 30^{\star}$ & $1.27,8.60$ & $1 \cdot 13^{*}$ & $1.02,4.17$ \\
\hline Random effects & $\operatorname{ICC} \ddagger$ & $95 \% \mathrm{Cl}$ & ICC $\ddagger$ & $95 \% \mathrm{Cl}$ & $\operatorname{ICC} \ddagger$ & $95 \% \mathrm{Cl}$ & $\operatorname{ICC} \ddagger$ & $95 \% \mathrm{Cl}$ \\
\hline State & $0.03^{*}$ & $0.00,0.05$ & $0.02^{*}$ & $0.01,0.04$ & $0.03^{*}$ & $0.01,0.05$ & $0.02^{*}$ & $0.01,0.03$ \\
\hline State/PSU & $0.09^{\star *}$ & $0.06,0.11$ & $0.06^{\star \star}$ & $0.05,0.08$ & $0.09^{\star \star}$ & $0.06,0.11$ & $0.05^{\star \star}$ & $0.04,0.07$ \\
\hline
\end{tabular}

ref., reference category; PSU, primary sampling unit; NA, not applicable; ICC, intraclass correlation.

${ }^{\star} P<0.05,{ }^{\star \star} P<0.001$.

tFrom equation (1) we use $\exp \left(\beta^{1}\right)$, which is the effect of a one-unit increase in the covariate on the odds of being underweight

IICC measures the proportion of the total unexplained variance attributable to differences between states/PSU after considering all independent variables in the model.

the likelihood of underweight for three of the four female subgroups at either $1 \%$ or $5 \% ; 5 \%$ and at $10 \%$ for urban young females. However, the nature and direction of this association differ across the population groups. Specifically, for young rural females, model results reveal there is a positive association between village education levels and the likelihood of underweight (i.e. parameter estimate $>1$ ). In contrast, for mature rural females the impact of village-level education has the opposite effect and is associated with a lower likelihood of underweight (i.e. parameter estimate $<1$ ). In the case of the urban young and mature female population groups there is a slight negative relationship.
Again, as with the wealth variable, we calculated the predicted probability of underweight for each subpopulation at different levels of neighbourhood education, which we divided into five percentage categories $(0,25,50,75$ and $100 \%)$ of the village/urban block women with $\geq 10$ years of education. The average probability for the two rural female subgroups is presented in Fig. 2.

For rural young females the average probability of underweight in villages where no one has $\geq 10$ years of education is $37.5 \%$, whereas in villages where $100 \%$ of the female population has $\geq 10$ years of education the average probability of underweight increases to $47.8 \%$. In contrast, 

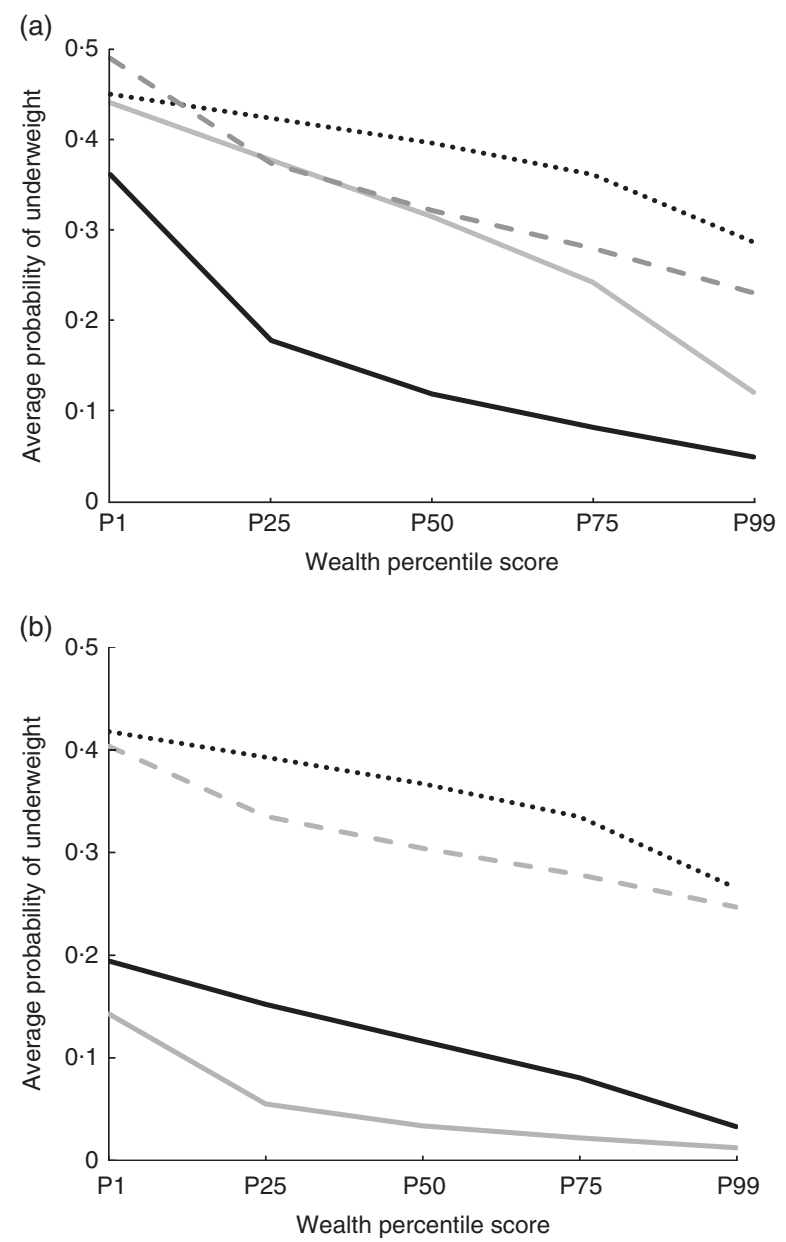

Fig. 1 Average probability of underweight for (a) females (urban mature females; $\_$, rural mature females; ......, rural young females; - - , urban young females) and (b) males ( - , urban mature males; $\_$, rural mature males; ......., rural young males; - - , urban young males) at different wealth points (P, percentile), India, 2005-06

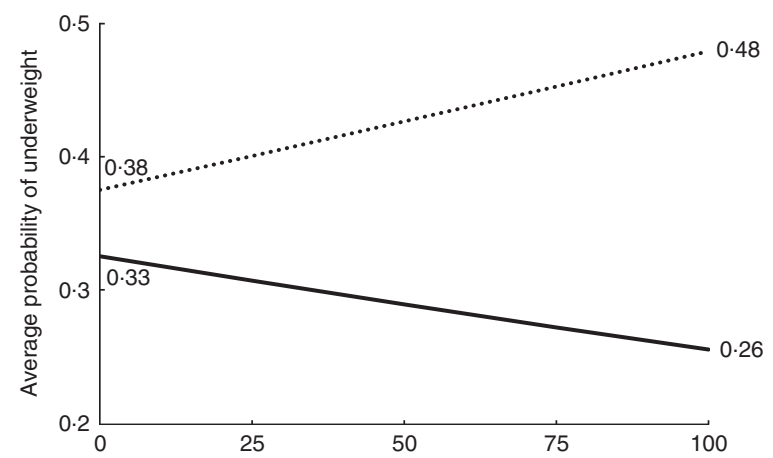

Proportion of adult females with $\geq 10$ years' education in the village (\%)

Fig. 2 Average probability of underweight for rural female subpopulation groups $\left(\cdots \cdots\right.$. , rural young females; $\_$, rural mature females) with respect to neighbourhood education level, India, 2005-06

for the rural mature female sub-population the average probability of underweight falls from 32.5 to $25.6 \%$, respectively, across the equivalent polar end points of neighbourhood education. The neighbourhood education variable is not statistically significant for any of the male sub-populations. We speculate on these paradoxical results in the 'Discussion' section.

With regard to economic inequality, the parameter estimate using the state-level Gini coefficient (i.e. 'state inequality') shows a strong positive association between the degree of inequality and the likelihood of underweight for nearly all sub-populations (only for urban mature females is there no statistical significance). Again, we transformed the likelihood ratio into a predicted probability of underweight at different levels of state (urban and rural) inequalities as measured by standardised Gini coefficients (Fig. 3(a) and Fig. 3(b)). The average probability of underweight for rural mature females at $2 \mathrm{SD}$ below the mean of state-level Gini coefficient is $22.1 \%$, which increases to $40.9 \%$ at $2 \mathrm{SD}$ above the mean. In the case of rural mature males the average probability of underweight for corresponding values of the state-level Gini coefficient is 17.3 and $38.0 \%$, respectively. Fig. 3(a) clearly shows that the positive association between the average probability of underweight and state-level inequality is particularly pronounced for the rural subpopulations. In the case of the young population groups, Fig. 3(b) shows that rising state-level inequality has a considerable positive impact on the probability of underweight across all four young sub-populations, with a relatively stronger effect in the rural environment.

A neighbourhood wealth inequality covariate included in the model (i.e. 'neighbourhood inequality') was measured by the CV of wealth at the PSU level. Model results presented in Tables 1 and 2 show that the neighbourhood wealth inequality parameter is statistically significant and positively associated with the likelihood of underweight for young (female and male) rural populations (i.e. parameter estimate <1). In Fig. 4 we show the effects on the average probability of underweight for rural young females and males with respect to neighbourhood inequality measured by percentile distribution in the wealth $\mathrm{CV}$. The average probability of underweight for rural young females is $36.5 \%$ at the first percentile of neighbourhood inequality whereas it increases to $42.7 \%$ at the 99th percentile. For rural young males, the average probability of underweight increases over the same percentile interval points from 41.4 to $48.1 \%$.

The model also included state-level monthly per capita expenditure (i.e. 'state per capita expenditure') as a proxy measure for the state's economic standard of living. The results show that higher state economic standard of living tends to be associated with a lower likelihood of underweight (i.e. parameter estimate $<1$ ). However, the extent of this expected negative association appears to be stronger for the male sub-populations relative to the female subpopulations. In terms of social infrastructure, the results show that rural young and mature females and rural young males with no access to toilet facilities have an increased 

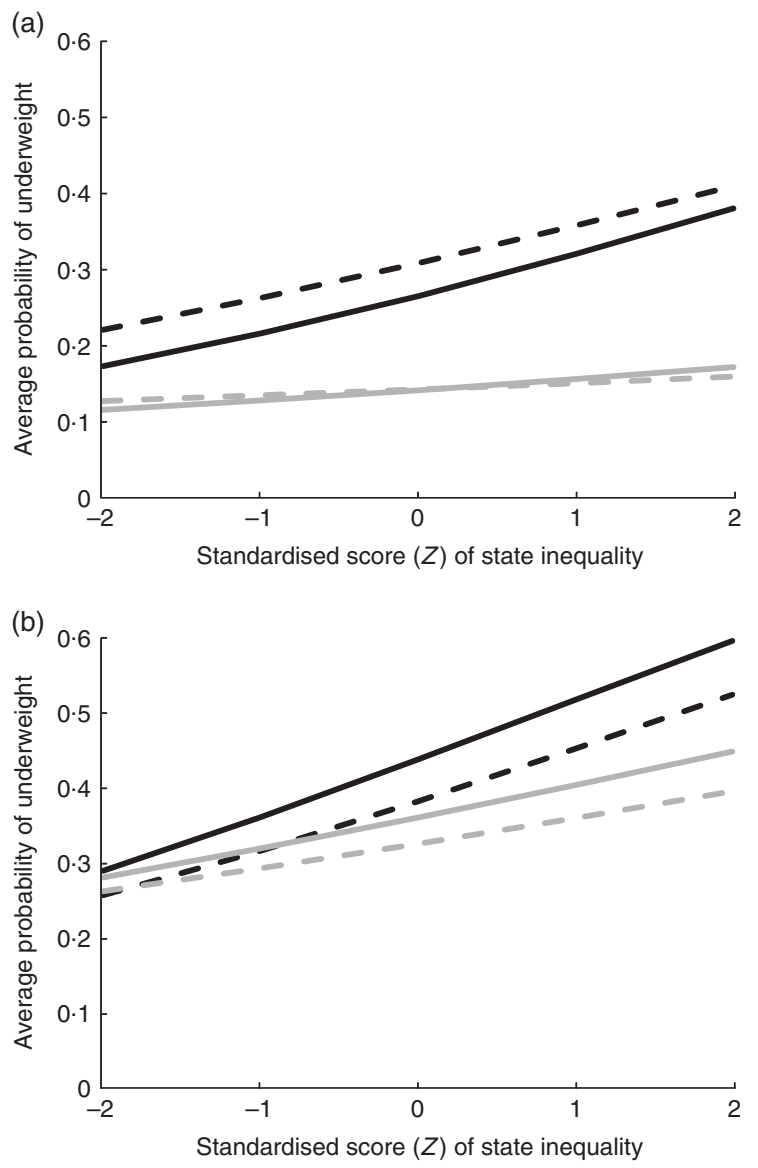

Fig. 3 Average probability of underweight for (a) the mature male and female sub-population groups (- - , rural mature females; - - , urban mature females; - , rural mature males; _ urban mature males) and (b) the young male and female sub-population groups (- - , rural young females; - - , urban young females; __ rural young males; $\_$, urban young males) with respect to state-level inequality (Gini coefficient), India, 2005-06. The state-level inequality parameter for the urban mature female subgroup is not statistically significant

likelihood of underweight with OR of 1.20, 1.11 and 1.16, respectively, relative to those who do have access to toilet facilities. This variable is not statistically significant for the urban sub-populations. With regard to the type of cooking fuel, the results reveal that rural mature females who have access to clean cooking fuel have a lower likelihood of underweight $(\mathrm{OR}=0 \cdot 80)$ relative to the reference group who use biomass as cooking fuel. Our model also finds that all employed males have a substantially lower likelihood of underweight $(\mathrm{OR}=0.56-0.72)$ relative to the reference group who do not work. For females, employment status exerts relatively little impact on the likelihood of underweight. Only for rural mature females engaged in manual work is there a statistical association of a higher likelihood of underweight $(\mathrm{OR}=1 \cdot 11)$ relative to non-working females.

Notwithstanding individual-level and macro-level contextual factors, multilevel analysis shows that unobserved

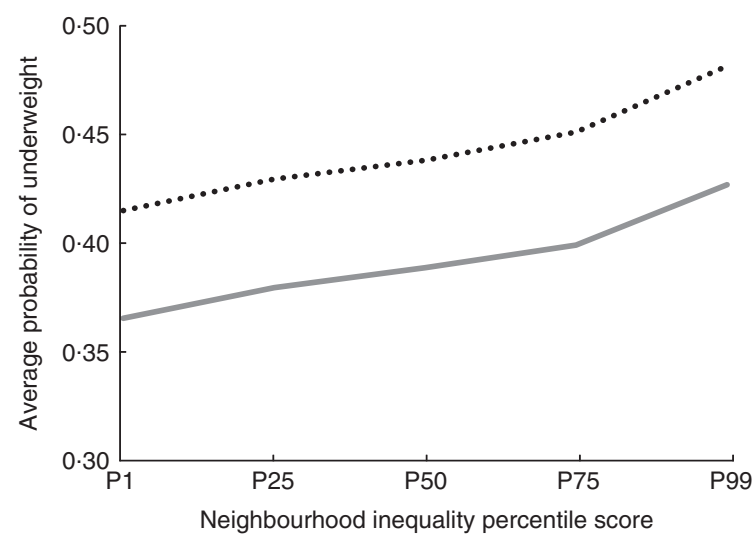

Fig. 4 Average probability of underweight for rural young female $(-)$ and rural young male $(\cdots . .$.$) population groups$ with respect to neighbourhood inequality (percentile (P) distribution in the CV of wealth), India, 2005-06

factors at state and PSU (village/urban block) levels still explain about 5-9\% of the total residual variance (measured by intra-class correlation). The twenty-nine Indian states were ranked in terms of the impact of statelevel unobserved factors on the likelihood of underweight. Due to space limitations, and given the higher prevalence rate of underweight in the rural sector, we show only results for the rural female sub-populations. The states are modelled as intercept shifts in their likelihood of underweight and, along with their $95 \% \mathrm{CI}$, are shown in the form of caterpillar plots (Fig. 5(a) and Fig. 5(b)).

Across the rural female sub-population groups some states have a statistically higher intercept than the all-India mean, which reflects a higher likelihood of underweight relative to the national benchmark. For example, Gujarat represents a major state whose likelihood of underweight lies statistically above the all-India mean. Although not shown here, our state-level analysis reveals that Gujarat stands out as a significantly 'above average' state in its likelihood of underweight for nearly all of the other subpopulation groups. It can be seen that other major states whose likelihood of underweight is statistically higher than the Indian mean include Bihar, Rajasthan, West Bengal, Jammu and Kashmir (Fig. 5(a) and Fig. 5(b)). Interestingly, the results also show that some of the relatively underdeveloped north-eastern states have a lower likelihood of underweight relative to the Indian mean (e.g. Arunachal Pradesh, Manipur and Meghalaya).

The multilevel analysis highlights that after allowing for individual-level and macro-level covariates, the state rankings in terms of the predicted probability of underweight (Fig. 5(a) and Fig. 5(b)) differ from the state rankings in the actual prevalence of underweight (see online supplementary material, Supplemental Table 2). In general, state-level effects are more pronounced in the female sub-populations compared with the male subpopulations; and although not shown here, they are more 

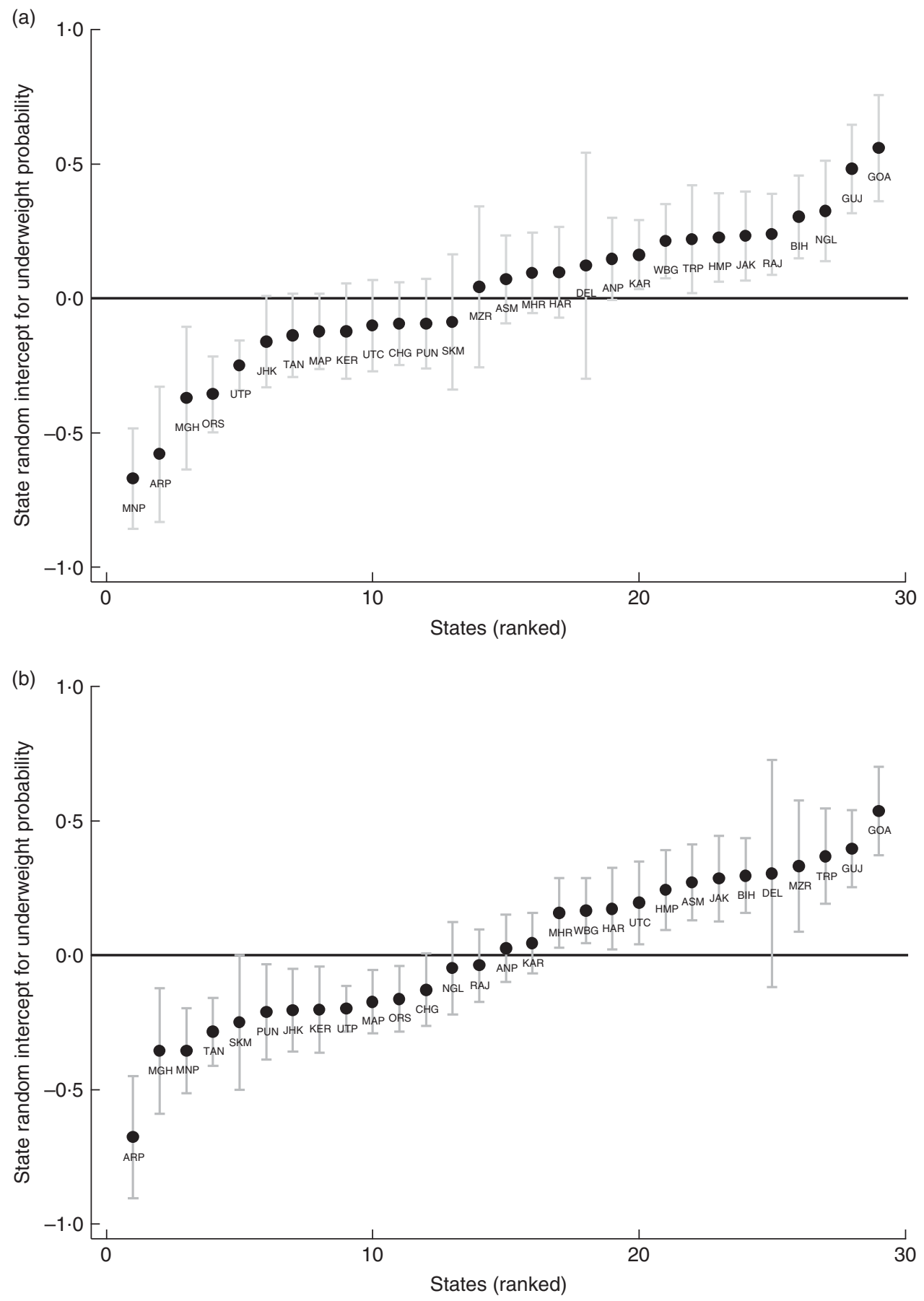

Fig. 5 State-level intercept effects for (a) rural young females and (b) rural mature females, India, 2005-06. Caterpillar plots of intercept shifts, with their $95 \% \mathrm{Cl}$ represented by vertical bars, showing the likelihood of underweight in twenty-nine Indian states relative to the Indian mean (at $y=0$ ); ANP, Andhra Pradesh; ARP, Arunachal Pradesh; ASM, Assam; BIH, Bihar; CHG, Chhattisgarh; DEL, Delhi; GOA, Goa; GUJ, Gujarat; HAR, Haryana; HMP, Himachal Pradesh; JAK, Jammu and Kashmir; JHK, Jharkhand; KAR, Karnataka; KER, Kerala; MAP, Madhya Pradesh; MGH, Meghalaya; MHR, Maharashtra; MNP, Manipur; MZR, Mizoram; NGL, Nagaland; ORS, Orissa; PUN, Punjab; RAJ, Rajasthan; SKM, Sikkim; TAM, Tamil Nadu; TRP, Tripura; UTC, Uttaranchal; UTP, Uttar Pradesh; WBG, West Bengal

pronounced in the rural setting than in the urban environment. As discussed in the 'Discussion' section, it is important to disentangle the sociocultural dimensions associated with particular regions from broader statebased attributes associated with economic development.

\section{Discussion}

The present study finds there are differing factors influencing the likelihood of underweight across adult sub-populations in India, based upon rurality, age/ 
maturity and gender. A social gradient exists in India, with higher wealth being associated with a lower likelihood of underweight across all sub-populations. However, across the wealth spectrum there are some considerable differences in the predicted probability of underweight between particular sub-populations which persist even at very high wealth levels. After allowing for wealth status, underweight inequality remains, with rural females in particular having a higher predicted probability of underweight relative to both urban female and all male sub-populations. Clearly, there is the need to understand the sociocultural norms and discriminatory practices influencing such outcomes.

The impact of education presents a particularly interesting issue. The study results suggest higher individuallevel education matters for males but not for females in reducing the likelihood of underweight. This finding is consistent with the view that in a historically patriarchal society a woman's education may have a limited influence on her own weight status relative to the influence of the education level of the male head of a household. We do not have information on the education levels of fathers of married females nor are we able to discern the influence of a husband's education on a wife's weight to explore this issue further. More research investigating the influence of male education levels on female BMI is required.

Interestingly also, our study finds that neighbourhood education matters for females but not for males. Paradoxically, rural young females living in more educated villages have a higher likelihood of underweight, whereas the opposite is the case for rural mature females whose greater neighbourhood education is associated with a lower likelihood of underweight. The only literature we are aware of which reveals a possible negative relationship between education and health outcomes are studies involving gender bias and discrimination. In India acute gender differences in infant and child mortality and morbidity have been well documented ${ }^{(15-19)}$. Here patriarchal institutions and social norms, including rules and rituals associated with caste and religion, establish power relations that discriminate against females in terms of household decision making, rules governing the allocation of resources and the rights to resources, and in the opportunities and obligations afforded to males and females ${ }^{(17,20)}$. This is manifested in adverse sex ratios, differential infant and childhood mortality, and different health care-seeking practices. In general, empirical results regarding the relationship between education and gender bias remain inconclusive. However, some studies have shown that gender bias in terms of differential health-care treatment for boys and girls and in male-female child ratios is higher among highly educated mothers and lower among less educated mothers ${ }^{(18,21)}$. The promulgation of this effect is through declining fertility rates associated with greater female education. The shift to smaller family size may intensify gender bias, as consideration is given to gender composition which may outweigh the changing preferences for sons that may come with greater female education $^{(22,23)}$.

Our analysis shows that the positive association between more educated villages and a higher likelihood of underweight is more pronounced for 15-19-year-olds than it is for 20-24-year-olds, but statistically significant for both age groups. However, for all subsequent age categories (i.e. mature females), higher educated villages/ neighbourhoods are associated with lower likelihood of underweight. Concerns have been raised regarding the ongoing discrimination faced by living girls ${ }^{(17)}$. One can speculate as to whether our study suggests that the concerns of gender bias may also extend to encompass rural young females in India, which diminishes with adult maturity. However, why neighbourhood/village-level education and not individual-level education matters in reducing the likelihood of underweight for rural and urban mature females is also unclear and further research regarding the influence of education on rurality, age/ maturity and gender is required.

Age itself represents an important influence on underweight. For young males in the 15-19 years category there is a very high underweight likelihood which drops dramatically in the 20-24 years category. This dramatic decline is not as acute among young females, suggesting that many males in the 15-19 years category are yet to reach adulthood physiologically. Given this, using conventional BMI measures of underweight for 15-19-year-old Indian males may be inadequate, such that aggregating this age bracket into a single population group is likely to be inappropriate when analysing the likelihood of underweight for adult males.

Study findings reveal that Christians have a lower likelihood of underweight across the sub-population groups even after allowing for individual-level and macro-level covariates. This outcome possibly could be attributed to the more egalitarian nature of the northeastern states, or to the higher levels of economic and social development in Kerala (state with a high Christian population), or that it represents particular sociocultural features reflected in dietary choices, sanitary behaviour and care-giving. Our results are consistent with a recently reported study on infant health in India which found that Christian infants have significantly better anthropometric outcomes than all other religious groups ${ }^{(24)}$. Further research into the underlying causal mechanisms linking sociocultural characteristics with the likelihood of underweight is required.

Some studies have highlighted that the persistent high prevalence of undernutrition in India is in part due to the lack of social infrastructure associated with sanitation and hygiene $^{(12,25,26)}$. Our findings are consistent with these studies. For the rural young sub-population groups, households with access to toilet facilities are associated with a lower likelihood of undernutrition. Compared with 
mature adults, younger adults are possibly more vulnerable to infections and ill-health from exposure to open defecation. In addition, we find that for rural mature females access to clean cooking fuel is associated with lower likelihood of underweight. This may be attributable to the avoidance of long exposure to toxic gases and pollutants when cooking with smoky biofuels ${ }^{(12)}$. The lack of social infrastructure in rural India appears to have impacted most acutely on rural young females in terms of higher likelihood of underweight.

The present study found that state-level economic inequality exerts an independent influence on the risk of underweight. Thus, individuals from poorer households residing in states with greater income inequality face a double burden in the risk of underweight. The relationship between the degree of state economic inequality and the risk of underweight appears more acute for rural males and females than for the urban sub-population groups and it is particularly pronounced among the younger population. Two reinforcing factors may contribute to these results. First, unequal states may provide lower levels of public and social health infrastructure relative to more egalitarian regions. Second, more unequal states may have poorer governance, greater inefficiencies and greater maldistribution of public infrastructure which is more readily accessible by the less poor than the poor ${ }^{(13,27,28)}$. Our findings reveal a positive relationship between village wealth inequality and the risk of underweight for rural young sub-populations. This positive relationship is not found for other sub-population groups. Greater wealth inequality at the village level may result in a greater disparity in the provision of local public amenities such as health facilities. Similarly, poor rubbish and sewerage disposal may exert a greater negative impact on the health of young adults than on mature adults.

Notwithstanding the inclusion of individual-level and macro-level covariates, the random components of multilevel analysis reveal that individual states and neighbourhoods/villages in those states still account for a part of the total prediction of underweight likelihood of individuals. Some particular states have consistently higher likelihood of underweight than an 'average' Indian state. In general, we find a degree of regional clustering of state residuals with a band of western states having a higher risk of underweight. Although Gujarat has been held up as an exemplar of economic development, an irony is that it is a state which is very much over-represented in the likelihood of underweight across all the sub-population groups $^{(29,30)}$. In contrast, we find that some of the underdeveloped north-eastern states have a lower likelihood of underweight relative to the Indian mean.

Several recent studies have pointed out that despite India's rapid economic growth in the 1990s-2000s this has not translated into improved economic and health outcomes for the poor and most vulnerable sections of the population, whose circumstances have not changed or have worsened under some measures ${ }^{(13,21,31,32)}$. Geographically related contextual factors matter and there is the need to understand the underlying causal mechanisms by which such effects are transmitted. It is unclear to what extent this situation is related to unmeasured macro-level environmental factors such as social and public health infrastructure or related to social influences and the role of social norms and cultural values embedded in dietary behaviour, sanitary and hygienic habits, and gender discrimination. From a policy perspective it becomes important to understand the salient characteristics of state-level and neighbourhood-level contextual factors and the patterning of risk of underweight across sub-population groups in terms of rurality, gender and age/maturity.

\section{Conclusion}

The persistence of undernutrition in India was described in 2008 by the then Prime Minister, Manmohan Singh, as 'a curse that we must remove' and he lamented at how strong economic growth had manifested the country into an 'economic powerhouse and a nutritional weakling'(27). Economic growth alone cannot solve India's crushing burden of undernutrition. The Indian subcontinent is characterised by considerable diversity, including differences in the scale of human and social development across regions and between rural and urban settings, and differences in the sociocultural environment such as race, religion, caste, social norms and customs. The present study shows that sub-population groups matter in terms of the factors governing the patterns of malnutrition both at the individual level and at the macro level incorporating state and neighbourhood/village contextual factors. For instance, individual-level education matters for males but not for females, whereas neighbourhood-level education matters for females but not for males although in paradoxical ways across the rural female sub-population groups. Similarly, the state-level and neighbourhood/ village-level inequalities, the level of social infrastructure and other macro-related contextual factors impact on the sub-population groups in different ways. Our study reveals that rural young females in particular tend to be most adversely affected by these problematic issues. Moreover, geographically related contextual factors associated with state/PSU random effects are also associated with the likelihood of underweight.

There is a considerable body of evidence which highlights that disparities in health are related to broader structural and socio-environmental factors; that is, the social determinants of health ${ }^{(33,34)}$. In addition to socioeconomic factors, health inequalities are influenced by where people are born, grow, live and age and the extent to which they have control over their circumstances ${ }^{(35)}$. Their circumstances are shaped by governance, how 
resources and power are distributed, cultural and social norms, and the broader social conditions in which one lives. Thus, in order to reduce health inequalities and to tackle the burden of malnutrition there is a need to understand the wider socio-economic, structural and environmental factors that contribute to such disparities. The present paper makes an initial contribution to this understanding by highlighting the differing effects of individual-level covariates and macro-level contextual factors influencing the patterning of underweight across particular sub-population groups in India.

\section{Acknowledgements}

Acknowledgements: The authors would like to thank Professor Srijit Mishra for his thoughtful comments during the preparation of this manuscript. Financial support: This research received no specific grant from any funding agency in the public, private or not-for-profit sectors. Conflict of interest: None. Authorship: Both authors formulated the research and analysed the data and also jointly shared in the writing of the manuscript. Ethics of buman subject participation: Ethics approval was not required.

\section{Supplementary material}

To view supplementary material for this article, please visit http://dx.doi.org/10.1017/S1368980016001968

\section{References}

1. Food and Agriculture Organization of the United Nations (2014) The State of Food Security in the World. Rome: FAO.

2. Deaton A \& Dreze J (2009) Food and nutrition in India: facts and interpretations. Econ Polit Wkly 44, 42-65.

3. Sen A (1992) Inequality Re-examined. New Delhi: Oxford University Press.

4. Jose S (2011) Adult undernutrition in India: is there a huge gender gap? Econ Polit Wkly 46, 95-102.

5. The World Bank (2006) Repositioning Nutrition as Central to Development: A Strategy for Large-Scale Action. Washington, DC: The World Bank.

6. Victora C, Adair L, Fall C et al. (2008) Maternal and child undernutrition: consequences for adult health and human capital. Lancet 371, 340-357.

7. Black R, Allen L, Bhutta Z et al. (2008) Maternal and child undernutrition: global and regional exposures and health consequences. Lancet 371, 243-260.

8. Caufield L, de Onis M, Blossner M et al. (2004) Undernutrition as an underlying cause of child deaths associated with diarrhoea, pneumonia, malaria and measles. Am J Clin Nutr 80, 193-198.

9. Ackerson L, Kawachi I, Bareau E et al. (2008) Geography of underweight and overweight among women in India: a multilevel analysis of 3204 neighbourhoods in 26 states. Econ Hum Biol 6, 264-280.

10. Subramanian S, Perkins J \& Khan K (2009) Do burdens of underweight and overweight coexist among lower socioeconomic groups in India? Am J Clin Nutr 90, 369-376.
11. Corsi D, Kyu H \& Subramanian S (2011) Socioeconomic and geographic patterning of under- and overnutrition among women in Bangladesh. J Nutr 141, 631-638.

12. Jose $S$ \& Navaneetham K (2010) Social infrastructure and women's undernutrition. Econ Polit Wkly 45, 83-89.

13. Subramanian S, Kawachi I \& Davey Smith G (2007) Income inequality and the double burden of under- and overnutrition in India. J Epidemiol Community Health 61, 802-809.

14. Mowafi M, Khadr Z, Subramanian S et al. (2011) Are neighbourhood education levels associated with BMI among adults in Cairo, Egypt? Soc Sci Med 72, 1274-1283.

15. Dreze J \& Sen A (2013) An Uncertain Glory: India and its Contradictions. Princeton, NJ: Princeton University Press.

16. Pande R \& Astone N (2007) Explaining son preference in rural India: the independent role of structural versus individual factors. Popul Res Policy Rev 26, 1-29.

17. Pande R \& Malhotra A (2006) Son Preference and Daughter Neglect in India: What Happens to Living Girls? New Delhi: International Centre for Research on Women.

18. Bhan G, Bhandari N, Taneja S et al. (2005) The effect of maternal education on gender bias in care-seeking for common childhood illnesses. Soc Sci Med 60, 715-724.

19. Murthi M, Guio A-C \& Dreze J (1995) Mortality, fertility and gender bias in India. Popul Dev Rev 21, 745-782.

20. Osmani S \& Sen A (2003) The hidden penalties of gender inequalities: fetal origins of ill-health. Econ Hum Biol 1, 105-121.

21. Chaudhri D \& Jha R (2013) India's gender bias in child population, female education and growing prosperity: 1951-2011. Int Rev Appl Econ 27, 23-43.

22. Echavarri R \& Ezcurra R (2010) Education and gender bias in the sex ratio at birth: evidence from India. Demography 47, 249-268.

23. Bhat P \& Zavier J (2003) Fertility decline and gender bias in northern India. Demography 40, 637-657.

24. Menon N \& McQueeney K (2015) Christianity and Infant Health in India. IZA Discussion Paper no. 9177. Bonn: Institute for Labour Studies.

25. Jose S (2014) Adult under-nutrition in India: poverty or ethnicity. Econ Polit Wkly 49, 72-74.

26. Chambers R \& Von Medeazza G (2013) Sanitation and stunting in India: undernutrition's blindspot. Econ Polit Wkly 48, 15-18.

27. Haddad L (2009) Lifting the curse: overcoming persistent undernutrition in India. IDS Bull 40, 1-8.

28. Kundu A (2003) In the Name of the Urban Poor: Access to Basic Amenities. New Delhi: Sage Publications.

29. The Economist (2015) The Gujarat Model. The Economist, 10 January 2015; available at http://www.economist.com/ news/finance-and-economics/21638147-how-modi-nomicswas-forged-one-indias-most-business-friendly-states

30. Jaffrelot C (2016) What 'Gujarat model'? - growth without development - and with socio-political polarisation. $S$ Asia 38, 820-838.

31. Subramanyam M, Kawachi I, Berkman L et al. (2010) Socioeconomic inequalities in childhood undernutrition in India: analysing trends between 1992 and 2005. PLoS One 5, e11392.

32. Subramanyam M, Kawachi I, Berkman L et al. (2011) Is economic growth associated with reduction in child undernutrition in India? PLOS Med 8, e1000424.

33. World Health Organization (2008) Closing the Gap in a Generation: Health Equity Through Actions on the Social Determinants of Health. Geneva: WHO.

34. World Health Organization (2010) Equity, Social Determinants and Public Health Programmes. Geneva: WHO.

35. Marmot M (2005) Social determinants of health inequality. Lancet 365, 1099-1104. 